\title{
Multiple Dermatofibromas on the Legs
}

\author{
${\text { Gabriel Salerni }{ }^{1,2} \text {, Carlos Alonso }}^{2}$
}

1 Dermatology Department, Hospital Provincial del Centenario de Rosario, Universidad Nacional de Rosario, Argentina

2 Diagnóstico Médico Oroño, Rosario, Argentina

Key words: dermatofibroma, fibrohistiocytoma, polarized light, imaging

Citation: Salerni G, Alonso G. Multiple dermatofibromas on the legs. Dermatol Pract Concept. 2020;10(4):e2020093. DOI: https://doi. org/10.5826/dpc.1004a93

Accepted: May 25, 2020; Published: October 26, 2020

Copyright: (02020 Salerni and Alonso. This is an open-access article distributed under the terms of the Creative Commons Attribution License BY-NC-4.0, which permits unrestricted noncommercial use, distribution, and reproduction in any medium, provided the original author and source are credited.

Funding: None.

Competing interests: The authors have no conflicts of interest to disclose.

Authorship: All authors have contributed significantly to this publication.

Corresponding author: Gabriel Salerni, MD, PhD, Bv. Oroño 1441, CP 2000, Rosario, Argentina. Email: gabrielsalerni@hotmail.com

\section{Case Presentation}

A 57-year-old woman presented to consultation complaining of the progressive appearance of skin lesions predominantly distributed in the lower limbs. The spontaneous occurrence of lesions began during adolescence, with continuous appearance of new lesions to the present. The patient was otherwise healthy, and there was no previous history of trauma, autoimmune diseases, immunodeficiency or use of immunosuppressive drugs. Cutaneous examination revealed firm brownish plaques and dome-shaped papules, ranging from $5 \mathrm{~mm}$ to 25 $\mathrm{mm}$ in diameter, with positive lateral dimple sign. The total number of lesions counted was greater than 180. Dermoscopy was consistent with dermatofibroma in all lesions (Figure 1).

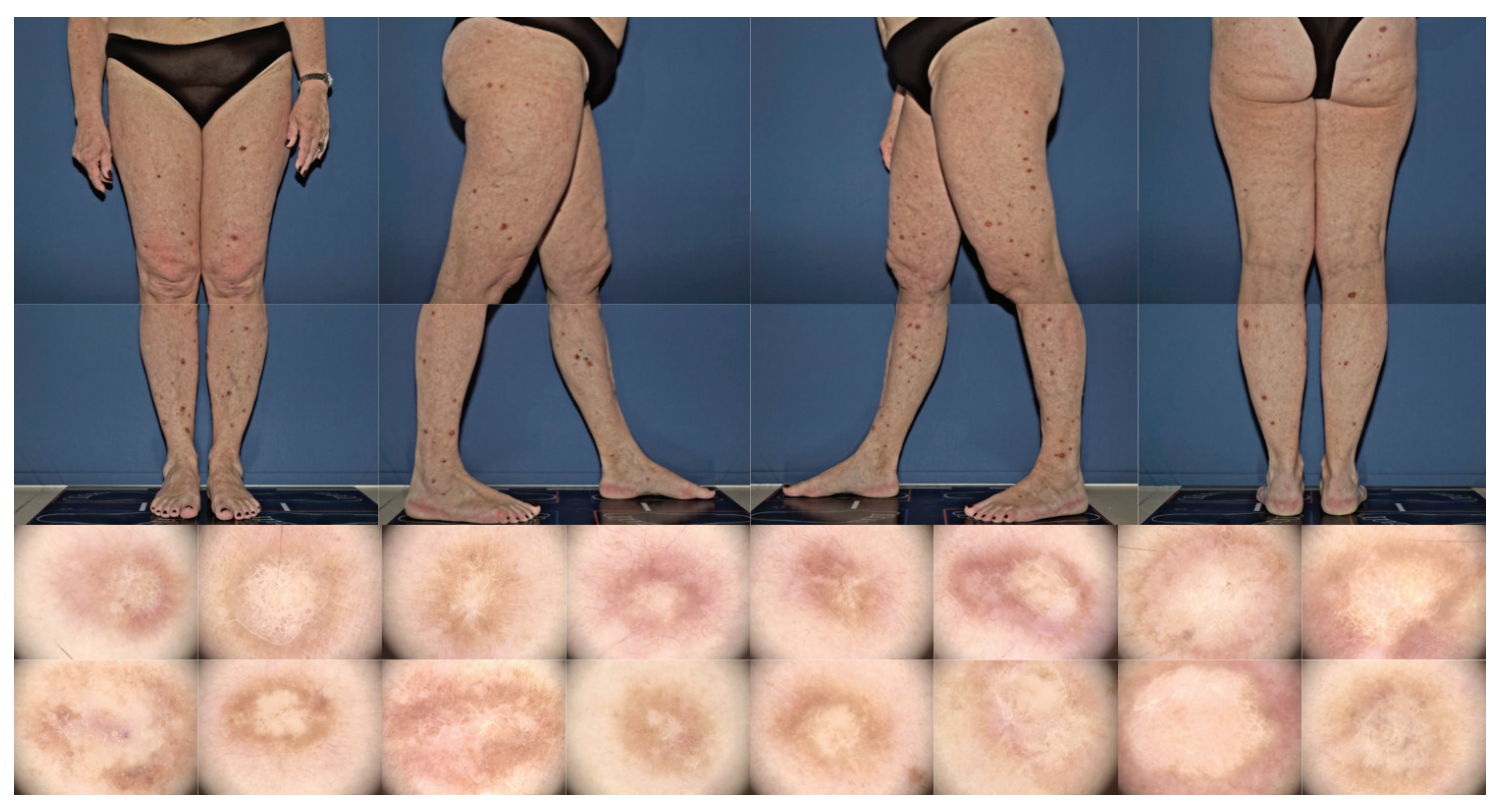

Figure 1. Dermoscopy was consistent with dermatofibroma in all lesions. 


\section{Teaching Point}

While solitary dermatofibromas may be incidental findings, multiple dermatofibromas may be associated with systemic conditions, such as autoimmune diseases, cancer, chromosomal abnormalities, immunodeficiency, metabolic disorders; or previous therapies [1,2]. The presence of many dermatofibromas in a patient without relevant associations, as in this case, is an even less frequent situation.

\section{References}

1. Her Y, Hyeon Ku S, Ho Kim K. A case of multiple eruptive dermatofibromas in a healthy adult. Ann Dermatol. 2014;26(4):539540. DOI: 10.5021/ad.2014.26.4.539. PMID: 25143694.

2. An I, Devran Gevher O, Esen M, Ibiloğlu I, Ecer N. Multiple eruptive dermatofibromas in a patient with systemic lupus erythematosus treated with methylprednisolone. Arch Rheumatol. 2018;33(2):236-237. DOI: 10.5606/ArchRheumatol.2018.6569. PMID: 30207570. 